\title{
Editorial
}

\section{Background on the Termination of Pregnancy Bill Debate in Malawi}

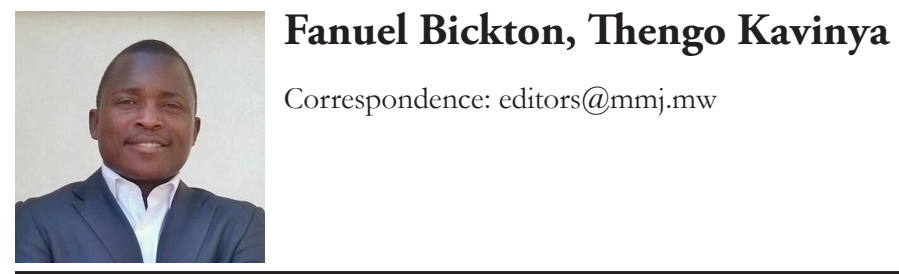

"Abortion" denotes the termination of pregnancy by any means, resulting in removal or expulsion of an immature, nonviable foetus or embryo of less than 28 weeks' gestation. ${ }^{1,2,3}$ An abortion can be spontaneous or induced. Spontaneous abortion, commonly referred to as miscarriage, is the unintentional expulsion of an embryo or foetus before the 28th week of gestation, while an induced abortion is that initiated by deliberate action undertaken with the intention of terminating pregnancy. ${ }^{4,5}$ According to sections 149 to 151, and section 243 of the Malawi Penal Code, the current position of the law is that induced abortion is illegal in Malawi, except where it is performed to save the life of the pregnant woman through a surgical operation. ${ }^{6}$ This law was introduced by the British in the 1930s and adopted by Malawi upon gaining independence in $1964 .{ }^{7}$ Under this law, any person administering an abortion is guilty and can be sentenced up to a maximum of 14 years imprisonment, while a pregnant woman who solicits an abortion can be jailed to a maximum of 7 years.

It is estimated that 42 million abortions occur across the world each year, and from this 20 million are unsafe induced abortions, and 70000 result in maternal death. ${ }^{8}$ Over 5 million women develop temporary or permanent disability as a result of abortion complications annually. ${ }^{8}$ Despite the legal restrictions in place on abortion in Malawi, the practice still occurs and is usually performed by untrained personnel or induced by pregnant women themselves. In 2009, a study by the Ministry of Health $(\mathrm{MOH})$ found that unsafe abortion is a significant contributor to almost $17 \%$ of maternal deaths in Malawi. This study, published in 2011, supported the empanelment of a Special Law Commission on the Review of the Law on Abortion (SLC) in 2013. ${ }^{9}$ Following two years of extensive consultation and deliberation, in February 2015 the SLC recommended liberalisation of the law on the evidence of the negative health impact of unsafe abortions, the high cost of providing post-abortion care (PAC), and citing Malawi's obligation to provide safe abortion provision as a signatory of the Maputo Protocol and other conventions. ${ }^{7}$

In view of the above, the SLC resolved and agreed that abortion law in Malawi be liberalised-that is, undergo conditional relaxation of the restrictions-but not decriminalised, to cater for certain justifiable grounds or instances where termination of a pregnancy should be permissible, namely: (1) where continued holding of pregnancy will endanger the life of a pregnant woman; (2) where termination is necessary to prevent injury to the physical or mental health of a pregnant woman, (3) where there is severe malformation of a foetus, which will affect its viability or compatibility with life; and (4) where the pregnancy is a result of rape, incest, or defilement. ${ }^{10}$ The proposed Termination of Pregnancy Bill, drafted by the SLC, is awaiting parliamentary debate and vote, though there is currently no timeframe for this.
In this special section of this issue of the Malawi Medical Journal, we commissioned opinion papers on this topic from prominent figures in the Malawi healthcare community: obstetrician-gynaecologist, Dr Chisale Mhango; members of the Christian Medical and Dental Fellowhip, Malawi; and bioethicist, Prof. Joseph Mfutso-Bengo.

\section{References}

1. Cunningham F, Leveno K, Bloom S, Hauth J, Rouse D, Spong C. Williams obstetrics. 23rd ed. New York: McGraw-Hill Medical; 2010.

2. Jeffcoate SN, Tindall VR. Jeffcoate's principles of gynaecology. London: Butterworth-Heinemann; 2014.

3. http://www.slideshare.net/Charliengo/legalisation-of-abortion-inmalawi

4. Konar H. DC Dutta's textbook of gynecology. 6th ed. New Delhi: Jaypee Brothers Medical Publishers; 2014.

5. Report of a WHO Scientific Group (1970): Spontaneous and Induced Abortion

6. Malawi Penal Code Sections 149-151, 243

7. Malawi Country Factsheet (2016) : Unsafe Abortion

8. Shah IH, Ahman E. (2009). Unsafe abortion: global and regional incidence, trends, consequences, and challenges. J Obstet Gynaecol Can. 2009 Dec;31(12):1149-58.

9. Ministry of Health of Malawi (2011)

10. http://www.maravipost.com/national/malawi-news/law-and-order /9316-unpacking-malawi-special-lawcommission-final-review $\% \mathrm{E} 2 \% 80$ \%99-findings-and-recommendation-on-abortion-law.html 